\title{
Projeto de Extensão de Basquetebol Adaptado no Contexto da Pandemia de Covid-19
}

\author{
Extension Project Adapted Basketball in The Context Of \\ The Pandemic of Covid-19
}

\section{Proyecto de Extensión de Baloncesto Adaptado em El Contexto de La Pandemia de Covid-19}

\author{
19 \\ Lana Ferreira De Lima \\ Universidade Federal De Catalão \\ (9) \\ Carolina De Fátima Guimarães \\ Universidade Federal De Catalão \\ (9) Leomar Cardoso Arruda \\ Universidade Federal De Catalão
}

Resumo: As incertezas impostas pela pandemia do Covid-19 provocaram a necessidade da extensão universitária se reinventar para continuar no cotidiano das comunidades. Este artigo apresenta as ações desenvolvidas, por meio das tecnologias digitais de informação e comunicação (TDIC's), para continuidade do Projeto de Extensão: "Basquetebol em Cadeira de Rodas: Inclusão, Saúde e Cidadania", quais sejam: 1) reuniões de planejamento pelo Google Meet; 2) aulas de dança, de atividades físicas e encontros do grupo terapêutico via WhatsApp ${ }^{\circ}$; 3) realização de webinars, por meio 
do StreamYard/Youtube, sobre atividade física e esporte adaptado. Conclui-se que as TDIC's possibilitaram a continuidade do projeto no período da pandemia, porém, enfrentamos dificuldades para garantir maior adesão dos participantes nas ações oferecidas por meio remoto.

Palavras-chaves: Basquetebol em Cadeira de Rodas. Extensão Universitária. Pandemia. Pessoa com Deficiência.

Abstract: The uncertainties imposed by the Covid-19 pandemic caused the need for university extension to reinvent itself to continue in the daily lives of communities. This article presents the actions developed, through digital information and communication technologies (TDIC's), for the continuity of the Extension Project: "Wheelchair Basketball: Inclusion, Health and Citizenship", namely: 1) planning meetings by Google Meet; 2) dance classes, physical activities and therapeutic group meetings via WhatsApp $\AA$; 3) hosting webinars, through StreamYard / Youtube, about physical activity and adapted sports. It is concluded that the TDIC's enabled the project to continue during the pandemic period, however, we face difficulties to ensure greater participation by the participants in the actions offered by remote means.

Keywords: Wheelchair Basketball. University Extension. Pandemic. Disabled Person.

Resumen: Las incertidumbres impuestas por la pandemia Covid-19 provocaron la necesidad de que la extensión universitaria se reinventara para continuar en el día a día de las comunidades. Este artículo presenta las acciones desarrolladas, a través de las tecnologías digitales de la información y la comunicación (TDIC's), para la continuidad del Proyecto de Extensión: "Baloncesto en silla de ruedas: inclusión, salud y ciudadanía", a saber: 1) reuniones de 
planificación por Google Meet; 2) clases de baile, actividades físicas y reuniones de grupo terapéutico vía WhatsApp $\left.{ }^{\circledR} ; 3\right)$ realización de webinars, a través de StreamYard / Youtube, sobre actividad física y deportes adaptados. Se concluye que los TDIC permitieron que el proyecto continuara durante el período pandémico, sin embargo, enfrentamos dificultades para asegurar una mayor participación de los participantes en las acciones ofrecidas por medios remotos. Palabras Clave: Básquetbol en Silla de Ruedas. Extensión Universitaria. Pandemia. Persona Discapacitada.

Data de submissão: 22/11/2020

Data de aprovação: 14/12/2020

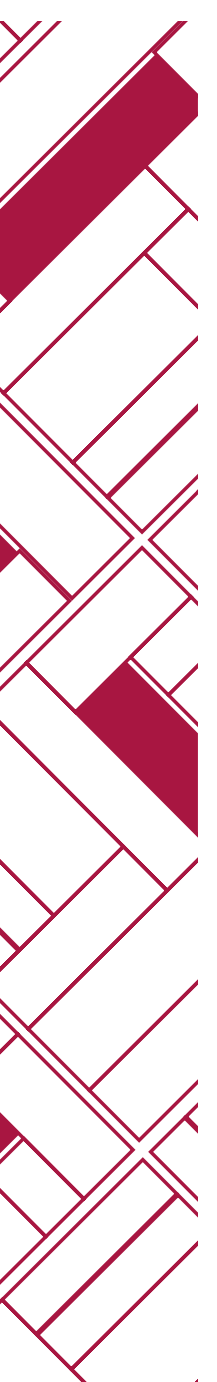


Projeto de Extensão de Basquetebol Adaptado no Contexto da Pandemia de Covid-19 Lana Ferreira De Lima • Carolina De Fátima Guimarães, et al...

\section{Introdução}

A COVID-19, doença provocada pelo novo coronavírus (SARS-CoV-2), surgiu em 2019 na China e, a partir de março de 2020, a Organização Mundial da Saúde (OMS) a caracterizou como pandemia e um dos maiores desafios sanitários em escala global deste século, provocando mudanças significativas no cotidiano das pessoas em decorrência das restrições impostas pelas regras do distanciamento social e devido aos novos hábitos de limpeza e higiene exigidos para combater a propagação do vírus.

Assim como os idosos e doentes crônicos, as pessoas com deficiência também são consideradas população de risco e suscetíveis a contrair o novo coronavírus (SARS-COV-2) devido aos cuidados diários de home care, equipe terapêutica e cuidadores para as atividades diárias, bem como o contato com diferentes equipamentos de locomoção como muletas, bengalas, cadeiras de roda.

O atual cenário é marcado por incertezas, o que pode desencadear episódios de ansiedade e maior vulnerabilidade. Nesse sentido, é importante construir recursos e redes sócio afetivas para amparar a população, especialmente as pessoas com deficiência.

Deparando-se com esta realidade, a Universidade viu-se frente a novos desafios, em que muitas perguntas foram aguçadas por aqueles que a compõem: o que fazer? Como ajudar? Como agir? Diante de tantas incógnitas, e, na necessidade de retomar e fortalecer o contato com a comunidade em tempos de pandemia, as Instituições de Ensino Superior (IES) se reorganizaram para o desenvolvimento das ações de extensão.

A extensão enquanto um processo educativo e científico que proporciona gerar e disseminar novos conhecimentos, se configura como o locus privilegiado da interação, diálogo e transforma- 
Projeto de Extensão de Basquetebol Adaptado no Contexto da Pandemia de Covid-19 Lana Ferreira De Lima • Carolina De Fátima Guimarães, et al...

ção entre a Universidade e a sociedade. Como afirma Abranches (2020) a extensão universitária planeja e desenvolve suas ações a partir, principalmente, dos interesses e necessidades compartiIhados entre a academia e a comunidade na qual se insere, num processo mútuo de aprendizagem.

Assim, uma das principais características da extensão está no seu caráter dialógico com a sociedade, porém no contexto da pandemia do COVID-19, que demandou o distancimento social, respeitando as orientações da OMS e dos cientistas brasileiros, muitas ações extensionistas, desenvolvidas em escolas públicas, unidades básicas de saúde, organizações sociais e no próprio espaço das Universidades, foram interrompidas e tiveram que se reinventar com vistas a manter o vínculo com as instituições/organizações, comunidades e com o público que atendiam.

Neste cenário uma das alternativas encontradas para manter o contato e o vínculo com o público das ações de extensão, respondendo assim os desafios postos, foi a realização de ações remotas por meio das tecnologias digitais de informação e comunicação (TDIC's).

\section{Objetivo}

Neste contexto este artigo visa apresentar as ações desenvolvidas por meio das TDIC's para continuidade do Projeto de Extensão: “Basquetebol em Cadeira de Rodas: Inclusão, Saúde e Cidadania", durante o período da pandemia do COVID-19.

\section{Fundamentação Teórica}

Historicamente, as pessoas com deficiência têm sido alvo de mecanismos e procedimentos de segregação, e até mesmo de exclusão na sociedade. A exclusão das pessoas com deficiência do 
Projeto de Extensão de Basquetebol Adaptado no Contexto da Pandemia de Covid-19 Lana Ferreira De Lima • Carolina De Fátima Guimarães, et al...

acesso a serviços (saúde, habitação, alimentação, trabalho, esporte, por exemplo) que Ihes garantam condições dignas de vida tem origens remotas, relacionadas ao contexto da organização econômica, social, política e cultural de cada sociedade, bem como ao conceito de homem e de educação que historicamente se transforma.

É possível afirmar, contudo, que nas três últimas décadas, como resultado da luta das próprias pessoas com deficiência, vem ganhando espaço na sociedade a proposta de romper com os tradicionais paradigmas excludentes, assim como a adoção de procedimentos que contribuam para assegurar a esse grupo de pessoas as condições necessárias à sua participação como sujeitos sociais de direito (CARVALHO, ROCHA, SILVA, 2006).

Assim, a mudança no que diz respeito à forma como a pessoa com deficiência passa a ser vista e tratada na sociedade, sendo reconhecida como um cidadão com direitos e deveres, ocorre principalmente a partir da aprovação de diversos documentos internacionais, de forma mais específica a Declaração Mundial sobre Educação Para Todos (UNESCO, 1990) e a Declaração de Salamanca e Linha de Ação sobre Necessidades Educativas Especiais (UNESCO, 1994), que reafirmam os direitos sociais de cada indivíduo, em específico a educação, conforme a Declaração Universal dos Direitos Humanos (ONU, 1948).

Nessa perspectiva, os autores Carvalho, Rocha e Silva (2006) afirmam que a partir da Declaração de Salamanca será proposto o paradigma da inclusão social que afirma a necessidade de todos os países se comprometerem com a eliminação das barreiras que vêm, historicamente, excluindo uma parcela considerável da população mundial, na qual se encontram as pessoas com deficiência. Esse paradigma tem como base a compreensão de que a todas as pessoas deve ser assegurado o pleno e efetivo exercício de todos os direitos humanos, sem distinção de qualquer espécie, 
Projeto de Extensão de Basquetebol Adaptado no Contexto da Pandemia de Covid-19 Lana Ferreira De Lima • Carolina De Fátima Guimarães, et al...

com plena igualdade perante a lei, bem como de participação em todos os aspectos da sociedade, tais como vida política, econômica, social, religiosa, cultural e no desenvolvimento de seu país.

Desse modo, na linha da garantia dos direitos humanos e da inclusão social, temos no âmbito legal, especificamente no Brasil, documentos que marcam a discussão acerca do direito de acesso a atividades de cultura, esporte e lazer às pessoas com deficiência tais como a Constituição de 1988 que foi elaborada e aprovada num contexto de crise econômica, de reivindicações políticas de vários segmentos da sociedade e de expectativas com o processo de "abertura" política do Brasil. Neste cenário, o governo passou a permitir e a estimular a criação e a organização de associações de certos segmentos da sociedade, inclusive dos grupos sociais considerados excluídos, entre os quais também se inseriam as entidades das próprias pessoas com deficiência, com o fim de participar em conselhos e órgãos gestores da administração pública (ROSA; ANDRÉ, 2006).

Neste período começa a se desenhar no cenário político brasileiro uma mudança nas atitudes das pessoas com deficiência, as quais historicamente tuteladas pelas famílias, instituições especializadas e pelo Estado, passaram a reivindicar o direito de participação e organização em condições de igualdade com os demais cidadãos sem deficiência. Assim, no quadro de redemocratização da sociedade brasileira, a Constituição de 1988, estabelece a garantia dos direitos individuais, políticos, a universalização dos direitos sociais, tais como, por exemplo, saúde, cultura, esporte e educação. Além disso, incorpora reivindicações pela "diferença" no plano cultural quando apresenta como princípios para nortear a legislação educacional, a ser elaborada em âmbito nacional, valores como justiça e igualdade, fraternidade e pluralidade. Em seu artigo $3^{\circ}$, a Constituição estabelece a garantia do desenvolvimento nacional, 
Projeto de Extensão de Basquetebol Adaptado no Contexto da Pandemia de Covid-19 Lana Ferreira De Lima • Carolina De Fátima Guimarães, et al...

por meio da organização de uma sociedade justa e solidária, sem preconceitos de origem, raça, sexo, cor, idade e quaisquer outras formas de discriminação. Além disso, propõe a erradicação da pobreza, da marginalização e da redução das desigualdades sociais e regionais (BRASIL, 1988).

Ao tratar dos direitos e deveres individuais e coletivos, o texto constitucional assegura que, perante a Lei, todos (homens e muIheres) são iguais e afirma, em seu artigo $6^{\circ}$, serem direitos sociais a educação, a saúde, o trabalho, a moradia, o lazer, o esporte, a segurança, a previdência social, a assistência aos desamparados bem como a proteção à maternidade e à infância (BRASIL, 1988). Nesse sentido, no artigo 217 da Constituição de 1988 é estabelecido como dever do Estado fomentar práticas desportivas formais e não formais, como direito de cada cidadão. Já no artigo 227, inciso II, fica determinada como função do Estado a criação de programas de integração social para a pessoa com deficiência, mediante o treinamento para o trabalho e a convivência, e a facilitação do acesso aos bens e serviços coletivos (LIMA, 2012).

Seguindo esta linha de raciocínio, temos também o Decreto Lei n³.298/1999 que regulamenta a Política Nacional para a Integração da Pessoa Portadora de Deficiência, que nos artigos $5^{\circ}$ e $6^{\circ}$, destaca como função do Estado e da sociedade civil o desenvolvimento de ação conjunta que assegure a plena inserção da pessoa com deficiência no contexto socioeconômico e cultural, portanto, em todas as iniciativas governamentais relacionadas à educação, à saúde, ao trabalho, à edificação pública, à previdência social, à assistência social, ao transporte, à habitação, à cultura, ao esporte e ao lazer.

Especificamente, no que concerne ao esporte, é explicitado no artigo $46^{\circ}$ que os órgãos e as entidades da Administração Pública Federal são direta e indiretamente responsáveis pelo deporto e 
Projeto de Extensão de Basquetebol Adaptado no Contexto da Pandemia de Covid-19 Lana Ferreira De Lima • Carolina De Fátima Guimarães, et al...

deverão desenvolver ações que possibilitem incentivar sua prática enquanto um direito de todos os cidadãos, conforme explicitado a seguir

\begin{abstract}
III - incentivar a prática desportiva formal e não-formal como direito de cada um e o lazer como forma de promoção social; IV - estimular meios que facilitem o exercício de atividades desportivas entre a pessoa portadora de deficiência e suas entidades representativas; V - assegurar a acessibilidade às instalações desportivas dos estabelecimentos de ensino, desde o nível pré-escolar até à universidade (BRASIL, 1999, não paginado).
\end{abstract}

Por sua vez no texto da Convenção Internacional sobre os Direitos das Pessoas com Deficiência e seu Protocolo Facultativo, promulgada no Brasil pelo Decreto $n^{\circ}$ 6.949/2009, afirma-se que este grupo de pessoas ainda enfrenta barreiras contra sua participação como membros iguais da sociedade e violações de seus direitos humanos em todas as partes do mundo. Nesse sentido, no inciso $V$ do artigo $30^{\circ}$, é afirmado que para lhes assegurar participar, em igualdade de oportunidades com os demais cidadãos, de atividades recreativas, esportivas e de lazer, os Estados-nação devem desenvolver medidas apropriadas que contribuam para incentivar, promover e assegurar a participação deste grupo de pessoas em atividades de caráter esportivo, como pode ser observado no trecho transcrito a seguir

a) Incentivar e promover a maior participação possível das pessoas com deficiência nas atividades esportivas comuns em todos os níveis; b) Assegurar que as pessoas com deficiência tenham a oportunidade de organizar, desenvolver e participar em atividades esportivas e recreativas específicas às deficiências 
Projeto de Extensão de Basquetebol Adaptado no Contexto da Pandemia de Covid-19 Lana Ferreira De Lima • Carolina De Fátima Guimarães, et al...

\begin{abstract}
e, para tanto, incentivar a provisão de instrução, treinamento e recursos adequados, em igualdade de oportunidades com as demais pessoas; c) Assegurar que as pessoas com deficiência tenham acesso aos locais de eventos esportivos, recreativos e turísticos (BRASIL, 2009, p. 15).
\end{abstract}

Nesse sentido, o esporte enquanto um bem cultural, construído historicamente pela humanidade, se configura com um direito social, que foi sendo delineado com o advento da sociedade industrial a qual consolida a divisão entre trabalho e tempo livre. O esporte voltado para a pessoa com deficiência, por sua vez, teve sua grande evolução após a Segunda Guerra Mundial, quando um de seus objetivos passa a ser o de reintegrar os soldados mutilados de guerra na sociedade e prevenir o sedentarismo (ARAÚjO, 1998).

Para Araújo (1998) esporte adaptado significa experiências esportivas modificadas ou especialmente designadas para suprir as necessidades especiais dos indivíduos. Seguindo essa linha de raciocínio Costa e Winckler (2012, p. 17) consideram que o esporte adaptado diz respeito à

$$
\begin{aligned}
& \text { [...] prática esportiva realizada pelas pessoas com deficiência } \\
& \text { visando a inclusão ou a melhora de suas funções motoras, } \\
& \text { podendo ter um caráter mais generalista ou especialista [...], } \\
& \text { baseado em modalidades que são adaptadas de esportes já } \\
& \text { existentes ou criadas especificamente para essa população, } \\
& \text { como o caso do Goalball. }
\end{aligned}
$$

O esporte adaptado se configura como uma porta de reinserção da pessoa com deficiência na sociedade, visto que a maioria dos atletas com deficiência, por meio da prática esportiva, retoma os ideais e os sonhos antes esquecidos. 
Projeto de Extensão de Basquetebol Adaptado no Contexto da Pandemia de Covid-19 Lana Ferreira De Lima • Carolina De Fátima Guimarães, et al...

Portanto, especificamente no caso de pessoas com deficiência, para além dos já conhecidos benefícios para a saúde física e mental, praticar esportes pode representar muito mais que meIhoria da condição cardiovascular, aprimoramento da força, da agilidade, da coordenação motora, do equilíbrio e do repertório motor. Isto porque, no aspecto social a prática de atividades esportivas contribui para tornar a pessoa com deficiência mais independente e autoconfiante no seu dia a dia, melhorando sua autoestima e tornando-a mais otimista e segura para alcançar seus objetivos, assim como proporciona a oportunidade de sociabilização entre pessoas com e sem deficiências.

É nessa perspectiva, que no contexto atual observamos um significativo desenvolvimento de recursos tecnológicos (construção, por exemplo, de próteses, cadeiras de rodas e materiais específicos de cada modalidade esportiva) para uso em um amplo leque de opções de modalidades esportivas como, por exemplo, acquaride (bóia-cross), artes marciais, curling em cadeira de rodas, esgrima em cadeira de rodas, tênis em cadeira de rodas, tacobol, mergulho adaptado, paracanoagem, goalball, natação, voleibol sentado, rugbi, basquete em cadeira de rodas, dentre outras que compõem um imenso universo de possibilidades.

Especificamente em relação ao basquete em cadeira de rodas, cabe dizer que, assim como outras modalidades esportivas criadas à época da Segunda Grande Guerra, este esporte foi desenvolvido, inicialmente, em centros de reabilitação nos Estados Unidos e Reino Unido com a finalidade de complementar o processo de reabilitação dos soldados que sofriam traumas provocados pelos confrontos nos campos de batalha (COSTA; WINCKLER, 2012).

Assim, considera-se que a primeira adaptação do basquete convencional (ou andante) para a prática com a cadeira de rodas ocorreu em 1944 na Inglaterra, no Hospital de Stoke Mandeville, 
Projeto de Extensão de Basquetebol Adaptado no Contexto da Pandemia de Covid-19 Lana Ferreira De Lima • Carolina De Fátima Guimarães, et al...

sob orientação do médico Sir Ludwig Guttmann que o utilizava como prática esportiva terapêutica no tratamento de seus pacientes. De lá pra cá este esporte alcançou grande desenvolvimento técnico, tático e tecnológico em virtude do aprimoramento constante das cadeiras de rodas para a sua prática (MARQUES; ALVES, 2012).

Este é um esporte cujas partidas do jogo (assim como o convencional/andante) são emocionantes, dinâmicas, rápidas e demandam capacidades e habilidades motoras para o atleta driblar, lançar, arremessar, passar a bola, pegar rebote, dentre outras habilidades, bem como, acima de tudo, espírito de equipe e altíssimo grau de integração sensório-motora (MARQUES; ALVES, 2012). É uma modalidade paralímpica que exige do atleta técnica apurada para o controle da bola e manuseio da cadeira e, assim como no esporte convencional/andante, “[...] o nível de aquisição e domínio de habilidades traz as mesmas características, ou seja, a deficiência não é fator de impedimento para a execução técnica dos fundamentos desse esporte" (Ibidem., p. 80).

Destaca-se, ainda, que o basquetebol em cadeira de rodas é uma das modalidades paralímpicas mais praticadas em âmbito mundial e que para garantir aos praticantes desenvolvimento técnico, tático e físico demanda-se, no contexto atual, por profissionais da área da Educação Física (e demais profissionais que direta ou indiretamente atuam com essa modalidade) com formação e conhecimentos sólidos sobre o esporte e deficiência (MARQUES; ALVES, 2012).

Não por acaso o Comitê Paralímpico Brasileiro, em parceria com o Ministério da Educação (MEC), tem desenvolvido, nos últimos anos, por meio do Programa Educação Paralímpica cursos para a formação e contínua qualificação e aprimoramento de professores de Educação Física para estimular o esporte como um dos elementos importantes para o desenvolvimento integral dos 
Projeto de Extensão de Basquetebol Adaptado no Contexto da Pandemia de Covid-19 Lana Ferreira De Lima • Carolina De Fátima Guimarães, et al...

alunos, assim como para discutirem e ensinarem esportes para pessoas com deficiência, grupo este que muitas vezes tem oportunidades reduzidas.

\section{Percurso Metodológico}

O Curso de Educação Física da Universidade Federal de Catalão (UFCAT) desenvolve, desde 2011, o Projeto de Extensão “Basquetebol em Cadeira de Rodas: Inclusão, Saúde e Cidadania", o qual tem o objetivo de promover a prática do basquetebol em cadeira de rodas, na perspectiva do trabalho de reabilitação, iniciação e aperfeiçoamento esportivo, com foco na inclusão social, por meio do desenvolvimento de metodologias de ensino-aprendizagem deste esporte adaptado, visando à ampliação da socialização, a autonomia e a autoestima das pessoas com deficiência de Catalão e região.

Além disso, esta ação de extensão visa: 1) Oportunizar o acesso das pessoas com deficiência ao basquetebol em cadeira de rodas; 2) Qualificar a equipe gestora do projeto quanto ao processo de ensino-aprendizagem das metodologias do ensino desta prática paradesportiva bem como sobre temas relativos à saúde, ao esporte adaptado e a inclusão social das pessoas com deficiência; 3) Proporcionar a participação das pessoas com deficiência, assim como da equipe gestora, em eventos esportivos, acadêmicos e culturais, no intuito de estimular o processo de inserção social desse grupo de pessoas por meio da prática do basquetebol adaptado em Catalão e região; 4) Estimular, por meio do esporte, o processo de reabilitação física e psicológica das pessoas com deficiência física e mobilidade reduzida; 5) Desenvolver um trabalho inter e multidisciplinar com diversas áreas do conhecimento da UFCAT, associações de pessoas com deficiência e instituições da cidade; 
Projeto de Extensão de Basquetebol Adaptado no Contexto da Pandemia de Covid-19 Lana Ferreira De Lima • Carolina De Fátima Guimarães, et al...

6) Divulgar a importância da inclusão social a partir da prática esportiva para as pessoas com deficiência física e com mobilidade reduzida; 7) Viabilizar a realização de palestras e oficinas com os participantes do projeto, e seus familiares, acerca da inclusão, acessibilidade e esportes adaptados.

A metodologia empregada na execução do Projeto constitui-se de reuniões semanais da equipe gestora, a qual se caracteriza por ser inter e multiprofissional visto envolver docentes e discentes do Curso de Educação Física e profissionais com formação na área da Psicologia. Estas reuniões perspectivam planejar e avaliar as ações a serem desenvolvidas ao longo da semana, bem como readequá-las caso seja necessário, para que atendam as singularidades dos participantes.

Além disso, são realizadas reuniões quinzenais para: a) planejamento e discussão das atividades a serem desenvolvidas nas aulas de basquete adaptado; b) realização de estudo sobre metodologias de ensino e pedagogia do esporte aplicadas ao basquetebol em cadeira de rodas; c) organização e planejamento das ações para execução de oficinas de basquetebol em cadeira de rodas em escolas (públicas e privadas) de Catalão e região; d) avaliação do desenvolvimento das aulas e das oficinas realizadas nas instituições de ensino.

Com vistas a garantir o desenvolvimento de um trabalho inter e multidisciplinar com as diversas áreas do conhecimento da UFCAT, associações de pessoas com deficiência e instituições da cidade, ao longo do período de realização da ação de extensão, busca-se realizar encontros de grupos de estudo e/ou rodas de conversa, bem como oficinas ou minicursos de curta duração (presenciais ou EAD) cujos temas são definidos a partir de demandas apresentadas durante o processo de desenvolvimento das ações do projeto de extensão (aulas de basquete). 
Projeto de Extensão de Basquetebol Adaptado no Contexto da Pandemia de Covid-19 Lana Ferreira De Lima • Carolina De Fátima Guimarães, et al...

Para além destas reuniões e encontros busca-se garantir aos monitores da ação de extensão a participação em eventos e oficinas sobre o tema do basquetebol em cadeira de rodas com o intuito de capacitá-los para o desenvolvimento das aulas no complexo esportivo do Curso de Educação Física que, anteriormente ao período da pandemia, ocorriam duas vezes por semana com duração de duas horas.

No cenário da pandemia do COVID-19 as atividades presenciais foram interrompidas e a equipe gestora do projeto repensou e adequou suas ações para este novo contexto, por meio de atividades remotas, com vistas a manter a continuidade da ação de extensão e o vínculo com o público atendido. Nessa perspectiva, a partir do mês de agosto de 2020, a equipe gestora retomou suas atividades por meio das reuniões semanais via Google Meet para planejamento e avaliação das atividades junto aos participantes do projeto.

Ainda no mesmo mês, a equipe consultou, por meio de ligações telefônicas, os quinze participantes do projeto (nove da cidade de Catalão-GO e seis de Araguari-MG), sendo treze homens e duas mulheres com idade entre 22 e 59 anos, o que permitiu que, a partir de agosto de 2020, por meio das TDIC's, fossem definidas as seguintes frentes de trabalho: 1) aulas de atividades físicas orientadas, duas vezes por semana, para participantes do projeto, por meio do aplicativo WhatsApp ${ }^{\circledR}$; 2) constituição de um grupo terapêutico com os participantes do projeto, quinzenalmente, via WhatsApp ${ }^{\circledR}$; 3) webinars mensais, por meio do StreamYard/Youtube, tratando de temas relativos ao esporte adaptado, capacitismo, deficiência e basquetebol em cadeira de rodas. 
Projeto de Extensão de Basquetebol Adaptado no Contexto da Pandemia de Covid-19 Lana Ferreira De Lima • Carolina De Fátima Guimarães, et al...

\section{Principais Resultados}

A partir do contato com os participantes, por meio de ligações telefônicas, foi identificado que: a) todos tiveram suas rotinas alteradas; b) quartoze pessoas possuem acesso a internet de banda larga e sem limite para uso de dados; c) quinze participantes utilizam o celular e dentre estes um total de cinco possuem, ainda, o computador/notebook; d) em termos de plataforma, para realizar vídeo chamadas, enviar/receber e fazer download de vídeos de atividade física orientada, a mais citada foi o aplicativo multiplataforma WhatsApp ${ }^{\circledR}$; e) todos informaram que suas residências possuem espaço para a prática de atividades físicas, bem como para participar de webconferência/vídeo chamada.

A partir dessas informações as aulas de basquetebol em cadeira de rodas foram retomadas por meio do aplicativo multiplataforma WhatsApp ${ }^{\circledR}$, de forma que duas vezes por semana são realizadas vídeo chamadas, com duração de quarenta minutos cada, durante as quais os participantes realizam, em suas residências alongamento, exercícios de fortalecimento e resistência muscular com e sem materiais alternativos, bem como atividades de fundamentos do basquetebol adaptado (manejo da cadeira, drible, passe e arremesso de bola) orientadas por monitores (um bolsista do Programa de Bolsas de Extensão e Cultura-PROBEC 2020/2021e uma discente voluntária) do Curso de Educação Física, contando com a adesão de três a seis participantes.

O contato com os participantes do projeto, por meio de ligações telefônicas, possibilitou à equipe gestora avaliar a necessidade de, para além da retomada das atividades físicas, garantir um espaço de diálogo e de orientações aos participantes da ação de extensão, neste momento de pandemia. Em face disso foi criado um Grupo Terapêutico, coordenado por duas psicólogas que par- 
Projeto de Extensão de Basquetebol Adaptado no Contexto da Pandemia de Covid-19 Lana Ferreira De Lima • Carolina De Fátima Guimarães, et al...

ticipam do projeto, com o objetivo de trabalhar questões ligadas à saúde mental dos participantes, em que as discussões são pautadas na reflexão sobre a condição da pessoa com deficiência.

Os encontros do Grupo Terapêutico, realizados quinzenalmente por meio do aplicativo WhatsApp ${ }^{\circledR}$, com duração de cinqüenta minutos, contando com a adesão de três participantes, têm sido um espaço para discussão dos desafios enfrentados por este grupo de pessoas na atualidade frente à pandemia. Desse modo, têm sido uma importante ferramenta para trabalhar os efeitos emocionais relatados pelos participantes frente à necessidade de distanciamento físico - principal recomendação sanitária para evitar o contágio pelo novo coronavírus.

As temáticas abordadas nos encontros do Grupo Terapêutico estão de acordo com o relatado com Cullen, Gulati e Kellen (2020). Segundo estes autores, os sujeitos tendem a apresentar adoecimento mental durante e após surtos de doenças infecciosas, pois as medidas de prevenção a COVID-19, bem como a incerteza quanto ao futuro podem desencadear sintomas relativos à, por exemplo, transtorno do pânico, ansiedade e depressão. Os sujeitos também tendem a apresentar sentimento de solidão e desamparo, principalmente diante da recomendação de distanciamento social.

O uso do aplicativo multiplataforma WhatsApp ${ }^{\circledR}$ para realizar as aulas de basquetebol em cadeira de rodas e os encontros do Grupo Terapêutico se mostrou a ferramenta mais viável, pois é uma das mais utilizadas e conhecidas pelos participantes e capaz de garantir uma interação à distância. Segundo Kola (2020), diante do atual cenário, uma das estratégias de atendimento em saúde mental é o uso das tecnologias digitais, pois, por meio de, por exemplo, smartphones é possível desde transmitir informações sobre programas de prevenção até atender pacientes com transtornos mentais graves, como as psicoses, sendo possível minimizar as consequências da situação pandêmica para a saúde mental (KOLA, 2020). 
Projeto de Extensão de Basquetebol Adaptado no Contexto da Pandemia de Covid-19 Lana Ferreira De Lima • Carolina De Fátima Guimarães, et al...

Considerando que dentre as ações/objetivos do projeto perspectiva-se a formação e qualificação da equipe gestora e, ainda, a realização de palestras, rodas de conversa e oficinas com os participantes do projeto, seus familiares e junto as associações de pessoas com deficiência e instituições da cidade, acerca da inclusão, acessibilidade, esportes adaptados, atividade física e qualidade de vida, os membros da equipe gestora da ação de extensão idealizaram o I Ciclo de Webinars em Atividade Física e Esporte Adaptado o qual foi realizado em parceria com os membros do Projeto de Extensão: Projeto Paralímpico Catalão: Esporte e Saúde para Pessoas com Deficiência.

Para que essa ação fosse efetivada a equipe executora se capacitou para a criação do canal Lafage-UFCAT na plataforma Youtube, bem como para a transmissão e disponibilização das webinars via StreamYard/Youtube. Avaliou-se sobre a importância da criação deste canal visto que poderia ser acessado por meio de diferentes recursos tecnológicos atingindo um público maior e garatindo a visibilidade das discussões realizadas e das ações do projeto.

Desse modo, no mês de setembro foi realizado o primeiro encontro do ciclo de webinars com o tema "Projeto Swoosh!: ferramenta administrativa da classificação funcional do basquetebol em cadeira de rodas", o qual trata-se de um projeto desenvolvido pelos discentes e docentes da Universidade Católica de Brasília (UCB). O segundo encontro, ocorrido em outubro, abordou o tema "Trajetórias de Vidas de Atletas no Esporte Paralímpico", com a participação de dois atletas do basquetebol em cadeira de rodas e de um paratleta catalano da equipe brasileira de atletismo. O terceiro e último encontro, ocorrido em novembro, tratou da temática "Capacitismo e Deficiência", com a participação de uma acadêmica que possui deficiência visual e cursa Ciências da Computação pela Universidade Estadual de Santa Cruz (UESC) e de uma 
Projeto de Extensão de Basquetebol Adaptado no Contexto da Pandemia de Covid-19 Lana Ferreira De Lima • Carolina De Fátima Guimarães, et al...

Psicóloga Clínica graduada pelo Centro Universitário São Francisco de Barreiras (UNIFASB).

\title{
Conclusão
}

As TDIC's mostraram-se como um recurso eficaz para a continuidade do Projeto de Extensão “Basquetebol em Cadeira de Rodas: Inclusão, Saúde e Cidadania", no período da pandemia, uma vez que a ferramenta Google Meet permitiu realizar as reuniões de planejamento e avaliação das ações pela equipe gestora. Além disso, por meio do aplicativo WhatsApp ${ }^{\circledR}$ foi possível não só retomar as aulas de basquetebol em cadeiras de rodas bem como constituir um Grupo Terapêutico, o que tem contribuído para manter o vínculo social e afetivo com os participantes da ação de extensão.

A formação e qualificação da equipe gestora, assim como a viabilização de espaços para discussão e reflexão com os participantes e seus familiares, acerca da inclusão, acessibilidade e esportes adaptados, foram ações garantidas por meio da realização das webinars transmitidas e disponibilizadas na plataforma StreamYard/Youtube-Lafage-UFCAT.

Concluímos que mesmo a equipe gestora do projeto procurando desenvolver ações mediadas por TDIC's acessíveis aos participantes, observou-se baixa adesão destes nas mesmas, aspecto este que se configura como um desafio para as ações de extensão desenvolvidas pelas IES.

\section{Referências}

\author{
ABRANCHES, M. EXTENSÃo UnIVERSITÁRIA REMOTA? OS DESAFIOS EM TEMPOS \\ de pandemia. Pensar a Educação em Pauta - um jornal para a educação \\ Brasileira, Belo Horizonte-MG, JUL.2020. DisPonível em: htTPS://PENSAR-
}


Projeto de Extensão de Basquetebol Adaptado no Contexto da Pandemia de Covid-19 Lana Ferreira De Lima • Carolina De Fátima Guimarães, et al...

AEDUCACAO.COM.BR/PENSARAEDUCACAOEMPAUTA/EXTENSAO-UNIVERSITARIA-REMOTA-OS-DESAFIOS-EM-TEMPOS-DE-PANDEMIA/. ACESSO EM: 19 Nov.2020.

ARaÚJO, P. F. de. Desporto adaptado no Brasil: origem, InStitucionalização e atualidades. Brasília, DF: Ministério da Educação e do Desporto: INDESP, 1998.

BRASIL. Lei No 13.146 de 6 de JULho de 2015. Institui a LeI Brasileira de Inclusão da Pessoa com Deficiência (Estatuto da Pessoa com Deficiência). BrasíliA, 2015. Disponível EM: HTTP://WWW.PLANALTO.GOV.BR/CCIVIL_03/_ ATO2015-2018/2015/LeI/L13146.HTM. ACESSO EM: 14 Nov.2020.

BRASil. Presidência da República. Decreto Nº 6.949, de 25 de agosto de 2009, promulga a Convenção Internacional sobre os Direitos das Pessoas com Deficiência e seu Protocolo Facultativo, assinados em Nova York, em 30 de MARÇo de 2007. Brasília, 2009. Disponível em: htTP://WWW. Planalto. GOV.BR/CCIVIL_03/_ATO2007-2010/2009/DECRETO/D6949.HTM. ACESSO EM: 14 Nov.2020.

BRASIL. Presidência da República. DeCreto N³.298, de 20 de dezembro de 1999, RegULAMENTA LEI No 7.853, DE 24 de OUTUBRO DE 1989, DISPÕE SOBRE a Política Nacional para a Integração da Pessoa Portadora de Deficiência, CONSOLIDA AS NORMAS DE PROTEÇÃO, E DÁ OUTRAS PROVIDÊNCIAS. BRASíLIA, 1999. DISPONÍVEL EM: HTTP://WWW.PLANALTO.GOV.BR/CCIVIL_03/DECRETO/D3298.HTM. ACESSO EM: 20 Nov.2020.

BRASil. Constituição (1988). Constituição da República Federativa do Brasil. Brasília, DF: Senado Federal, 1988.

CARVALHO, A. R. DE; ROCHA, J. V. DA; SILVA,V. L. R. R. DA. PESSOA COM DEFICIÊNCIA NA HISTÓRIA: MODELOS DE TRATAMENTO E COMPREENSÃO. IN: PROGRAMA INSTITUCIONAL DE AÇÕES RELATIVAS ÀS PESSOAS COM DEFICIÊNCIA (Org.). Pessoa COM deficiênCIA: ASPeCtOS teÓRICOS E PRÁtI- 
Projeto de Extensão de Basquetebol Adaptado no Contexto da Pandemia de Covid-19 Lana Ferreira De Lima • Carolina De Fátima Guimarães, et al...

cos. Cascavel/PR: Gráfica da Universidade Estadual do Oeste do Paraná (UNIOESTE), 2006. P.20-33.

COSTA, A. M. da; WINCKLER, C. A Educação Física e o esporte Paralímpico. In: MEllo, M. T.; WinCKLeR, C. Esporte Paralímpico. São Paulo: Editora Atheneu, 2012. P. 15-20.

CUllen, W.; GUlati, G.; KELly, B. D. Mental health in the Covid-19 Pandemic. QJM: An International Journal of Medicine, v. 113, N. 5, P. 311-312, 2020. DiSPONÍVEL EM: HTTPS://ACADEMIC.OUP.COM/QJMED/ARTICLE/113/5/311/5813733. ACESSO EM: 20 NOV. 2020.

KOlA, L. Global mental health and COVID-19. The Lancet Psychiatry, v. 7, N. 8, P. 655-657, 2020. DisPONÍVEL EM: HTTPS://WWW.THELANCET.COM/ JOURNALS/LANPSY/ARTICLE/PIIS2215-0366(20)30235-2/FULLTEXT. ACESSO EM: 20 Nov. 2020.

21

LIMA, L. F. DE L. InCLUSÃo SócIO-EduCACIONAL E DIVERSIDAdE: DEBATE CONCEITUAL E DESENVOLVIMENTO hISTÓRICO-LEGAL No BRASIL APÓs 1988. 2012. 180F. Tese (Doutorado em Educação) - Faculdade de Educação, Universidade Federal de Minas Gerais, Belo Horizonte-MG. 2012.

MARQUES, R. D.; ALVES, M. A. F. Basquete EM CAdeIRA de ROdAS. IN: MEllo, M. T.; WinCKLER, C. Esporte Paralímpico. São Paulo: Editora Atheneu, 2012. P. 75-82.

ORGANIZAÇÃO DAS NAÇÕES UNIDAS (ONU). DECLARAÇÃo UNIVERSAL dos Direitos Humanos. New York, 1948. Disponível em: Disponível em: HTTP://WWW.ONUBRASIL.ORG.BR/DOCUMENTOS_DIREITOSHUMANOS.PHP.ACESSO EM: 14 Nov.2020.

ORGANIZAÇÃO DAS NAÇÕES UNIDAS PARA A EDUCAÇÃO, A CIÊNCia e a CUltura. Declaração de Salamanca e Linha de ação sobre NeCESsidades educativas especiaIs. BRAsília: UNESCO, CORDE, 1994. 54P. 
